(2) Open Access Full Text Article

REVIEW

\title{
Potential role of linagliptin as an oral once-daily treatment for patients with type 2 diabetes
}

This article was published in the following Dove Press journal:

Diabetes, Metabolic Syndrome and Obesity:Targets and Therapy

22 August 2012

Number of times this article has been viewed

\section{Lene Hoimark \\ Torben Laursen \\ Jørgen Rungby}

Department of Biomedicine Pharmacology and Clinical Pharmacology, Aarhus University Hospital and Aarhus University,

Aarhus, Denmark
Correspondence: Lene Hoimark Department of Biomedicine Pharmacology and Clinical Pharmacology, Wilhelm Meyers Alle, BIdn 1240,

Aarhus University,

DK-8000 Aarhus C, Denmark

Tel $+4526 \mid 33926$

Fax +4586128804

Email lene.hoimark@farm.au.dk
Background: Linagliptin is an oral antihyperglycemic agent that selectively inhibits the enzyme dipeptidyl peptidase-4 (DPP-4). Inhibition of DPP-4 increases the levels of the incretin hormones glucagon-like peptide and glucose-dependent insulinotropic polypeptide by preventing their degradation.

Objective: We reviewed the role of linagliptin as an oral once-daily treatment for patients with type 2 diabetes.

Methods: A comprehensive literature search was performed using the term "linagliptin." Original research articles and review articles were included in our examination.

Results: Linagliptin has a similar mode of action as other gliptins, with comparable efficacy, safety profile, and tolerability. Differences in pharmacokinetic parameters that distinguish linagliptin from other gliptins include that linagliptin is not renally excreted and does not require dose reduction with renal impairment.

Conclusion: Linagliptin is an oral, once-daily, antihyperglycemic agent that significantly reduces glycated hemoglobin $\left(\mathrm{HbA}_{1 \mathrm{c}}\right)$ when used alone or in combination with other antidiabetic drugs in people with type 2 diabetes. Pharmacokinetics, such as the lack of renal excretion, distinguishes linagliptin from other gliptins.

Keywords: DPP-4 inhibitors, linagliptin, type 2 diabetes

\section{Introduction}

Dipeptidyl peptidase-4 (DPP-4) inhibitors are members of a class of oral antihyperglycemic agents that have been introduced as a new treatment option for monoand combination therapy of type 2 diabetes mellitus (T2DM). ${ }^{1}$

DPP-4 inhibitors antagonize the serine peptidase DPP-4, which is responsible for the rapid cleavage of the endogenous incretin hormones glucagon-like peptide (GLP-1) and glucose dependent insulinotropic polypeptide (GIP) in vivo. ${ }^{2}$

Following food intake, GLP-1 and GIP regulate the action of insulin. Glucagon secretion is also decreased by GLP-1, which, in turn, reduces hepatic gluconeogenesis.

Prolonging the half-life of these two incretins augments glucose-dependent insulin secretion, inhibits endogenous glucose production, and lowers blood glucose. ${ }^{3}$ DPP-4 inhibitors have been shown to reduce both fasting and postprandial glucose levels, leading to a reduction of $\mathrm{HbA}_{1 \mathrm{c}}$, with minimal risk of hypoglycemia and the absence of weight gain. ${ }^{2}$

GLP-1 analogs also delay gastric emptying and reduce appetite. DPP-4 inhibitors improve beta-cell function. ${ }^{2}$ Animal models and human data from clinical studies 
suggest that exposure to DPP-4 inhibitors and GLP-1 analogs may increase the survival of beta-cells. ${ }^{3}$

\section{Chemistry of linagliptin}

Linagliptin (BI 1356) is a xanthine-based orally administered, potent, and long-acting non-peptidomimetic DPP-4 inhibitor that has been developed for treating T2DM (Figure 1).

Linagliptin shows high selectivity for DPP-4 versus DPP-8 (40.000-fold) and DPP-9 (>10.000-fold) compared to the others gliptins, but is less selective for fibroblast activation protein, alpha (FAP alpha/separase) (89-fold). ${ }^{2}$

Linagliptin inhibits DPP-4 with a half-maximal inhibitory concentration $\left(\mathrm{IC}_{50}\right)$ of approximately $1 \mathrm{nM}$, which is much lower than that of sitagliptin (19 nM), alogliptin (24 nM), saxagliptin (50 nM), and vildagliptin (62 nM). ${ }^{4}$

\section{Regulation of use}

Linagliptin has recently been approved for use in the USA, Japan, and Europe for treating T2DM. The drug has been approved for monotherapy or in combination with other commonly prescribed medications for T2DM, such as metformin, sulfonylureas, and pioglitazone. Thus, it adds to the armamentarium of other DPP-4 inhibitors, such as saxagliptin and sitagliptin, which are currently approved for use in the US (2009 and 2006) and Europe (2009 and 2007). Vildagliptin is approved in Europe by the European Medicines Agency (EMA, 2007), but not in the US, and alogliptin has been approved only in Japan (2010). ${ }^{5-7}$

\section{Similarities and differences between gliptins}

DPP-4 inhibitors are all small molecules for oral use. They are to some extent similar to gliptins in their mode of action (incretin enhancers), efficacy in terms of lowering of glycated hemoglobin $\left(\mathrm{HbA}_{1 \mathrm{c}}\right)$ levels, safety profile, and patient tolerance. At therapeutic doses, all DPP-4 inhibitors reduce plasma DPP-4 activity by $70 \%-90 \%$ in a sustained manner

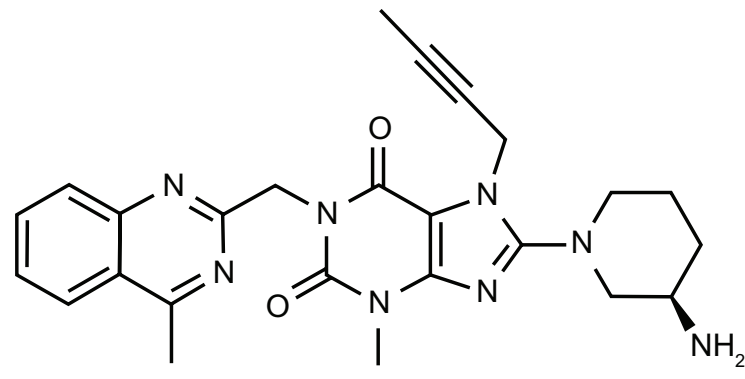

Figure I Chemical structure of linagliptin. (over $24 \mathrm{~h}$ ) and provide clinically meaningful increases in GLP-1 levels (1.5-4-fold).

DPP-4 inhibitors differ in terms of absorption, distribution, metabolism, and elimination, as well as in their potency and duration of action. Saxagliptin and vildagliptin are metabolized in the liver. Vildagliptin is primarily catabolized by hydrolysis $(55 \%)$ to an inactive metabolite. Sitagliptin undergoes limited metabolism by CYP3A4 and CYP2C6, forming inactive metabolites. Linagliptin is excreted nearly unchanged by the liver, in contrast to other DPP-4 inhibitors which are eliminated primarily via the kidneys. Saxagliptin can participate in cytochrome-mediated drug-drug interactions, but does not interact with other gliptins. Vildagliptin is recommended for twice-daily administration for a 24-h effect. Inhibition of DPP-4 activity by vildagliptin has been shown to be reduced to $35 \%$ at 24 -h for the $100-\mathrm{mg}$ dose and to $<70 \%$ for doses above $100 \mathrm{mg}$. At 12.5 hours post-dosing, 90\% inhibition of DPP-4 activity was retained for doses above $100 \mathrm{mg}$. DDP-4 inhibition of at least $80 \%$ is required to enhance GLP-1 and GIP (another stimulator of insulin secretion) levels to obtain a clinically relevant effect; therefore, vildagliptin must be administered twice daily. Other DPP-4 inhibitors on the market are administered once daily. ${ }^{7,8}$

\section{Pharmacokinetics of linagliptin Absorption}

The absolute bioavailability of linagliptin has been estimated to be $29.5 \%$, with a high interindividual variability of $46.7 \%$ (range 12.9\%-60.8\%). ${ }^{9}$

Linagliptin is rapidly absorbed; time to reach maximum plasma concentration $\left(\mathrm{T}_{\max }\right)$ values range from 0.7 to $2 \mathrm{~h}$ for different doses (200-2.5 mg) ${ }^{10}$ In human studies, the median time to reach maximum plasma concentration $\left(\mathrm{C}_{\max }\right)$ of linagliptin after oral administration was generally 90 minutes. $^{10,11}$

Food has been shown to reduce the rate but not the extent of linagliptin absorption, suggesting that food has no relevant influence on the efficacy of linagliptin. ${ }^{11}$

\section{Distribution}

After single and multiple oral doses, linagliptin follows nonlinear pharmacokinetics, with a less than dose-proportional increase in exposure in the therapeutic dose range. ${ }^{11}$ It has been shown that concentration-dependent protein binding to the target, DPP-4, is the primary cause of the observed nonlinearity. ${ }^{9}$ Plasma protein binding of linagliptin decreased from approximately $99 \%$ at $1 \mathrm{nmol} / \mathrm{L}$ to $70 \%-80 \%$ at $>100 \mathrm{nmol} / \mathrm{L} .{ }^{12}$ At low plasma concentrations, linagliptin is 
predominantly bound to its target DPP-4, and only a small fraction of free DPP-4 can be eliminated. With increasing plasma concentrations, linagliptin readily saturates DPP-4, resulting in an increased free fraction and increased volume of distribution and clearance. Because of the non-linear pharmacokinetics, many pharmacokinetic parameters for linagliptin increase with higher doses; for example, the terminal half-life $\left(t_{1 / 2}\right)$ is prolonged ( $>100$ hours). Time to steady-state is reached within 2-4 days. ${ }^{9,12}$ Steady-state volume of distribution (Vss) increased with doses of 380-1540 L.9

\section{Elimination}

Metabolism only minimally contributes to the overall disposition and elimination of linagliptin in humans. Linagliptin is primarily eliminated unchanged via the feces, by which $84.7 \%$ of an oral dose is eliminated. Renal excretion is low, approximately $5.4 \%$ (15)-1\% (11) of a dose.

The main metabolite of linagliptin (CD1790), which accounts for $>10 \%$ of the total drug-related compounds, is pharmacologically inactive. The metabolites of linagliptin play a minor role in the overall disposition and elimination of linagliptin. Renal excretion of CD1790 is less than $0.1 \%$.

In vitro studies have identified linagliptin as a substrate for and a weak inhibitor of cytochrome (CYP) $3 \mathrm{~A} 4 .^{8}$ The cytochrome $\mathrm{P} 450$ system plays a minor role in the metabolism of linagliptin, and hence therapeutic doses linagliptin are likely to have a weak potential for clinically relevant interactions with drugs metabolized via this system. ${ }^{13}$

Thus, in contrast to other DPP-4 inhibitors, renal excretion is a less important elimination pathway for linagliptin at therapeutic dose levels, and dose adjustment in renal impairment is not necessary for linagliptin. ${ }^{10}$

The main parmacokinetic characteristics of five dipeptidylpeptidase- 4 inhibitors can be seen in the review of gliptins by Scheen. ${ }^{8}$

\section{Gender}

Gender had no clinically relevant effect on the pharmacokinetics of linagliptin based on a population pharmacokinetic analysis of Phase I and Phase II data, and thus no dosage adjustment is necessary based on gender.

\section{Geriatric}

No dosage adjustment is required based on age up to 80 years, as age did not have a clinically relevant impact on the pharmacokinetics of linagliptin based on a population pharmacokinetic analysis of Phase I and Phase II data.
In elderly as well as younger subjects, plasma concentrations were comparable.

\section{Race}

No dosage adjustment is necessary based on race, as race had no obvious effect on the plasma concentrations of linagliptin based on a composite analysis of available pharmacokinetic data, including patients of Caucasian, Hispanic, African, and Asian origin. Additionally, the pharmacokinetic characteristics of linagliptin were found to be similar in dedicated phase I studies in Japanese, Chinese, and Caucasian healthy volunteers. ${ }^{14}$

\section{Pharmacodynamics of linagliptin/ DPP-4 inhibitors Mechanism of action}

Linagliptin is an inhibitor of the enzyme DPP-4, which is involved in inactivation of the incretin hormones GLP-1 and GIP. These hormones are rapidly degraded by DPP-4. Both incretin hormones are involved in the physiological regulation of glucose homeostasis. Incretins are secreted in low basal amounts throughout the day, and levels increase immediately after food intake. GLP-1 and GIP increase biosynthesis and secretion of insulin in the presence of normal and elevated blood glucose levels. Furthermore, GLP-1 reduces glucagon secretion, resulting in a reduction in hepatic glucose output. Linagliptin binds very effectively to DPP-4 in a reversible manner, leading to a sustained increase in and prolongation of active incretin levels. Like GLP-1, linagliptin glucosedependently increases insulin secretion and lowers glucagon secretion, resulting in an overall improvement of glucose homoeostasis. ${ }^{14}$

\section{Efficacy}

A direct correlation exists between DPP-4 activity and linagliptin plasma concentrations. It has been estimated that $5 \mathrm{mg}$ linagliptin results in approximately $80 \%$ DPP-4 inhibition, showing a clinically meaningful glucoselowering effect in people with diabetes. Single doses of linagliptin of up to 120 times the proposed clinically effective dose level (ie, $5 \mathrm{mg}$ daily) were well-tolerated in healthy male subjects with an adverse events (AE) profile similar to that of placebo. The effect of linagliptin is long-lasting and does not return to baseline for 96 hours after drug administration. ${ }^{10}$

At 24 weeks, linagliptin vs placebo has been shown to reduce $\mathrm{HbA}_{1 \mathrm{c}}$ by $0.69 \%$ from baseline $(P<0.0001)$, improving fasting plasma glucose by $1.3 \mathrm{mmol} / \mathrm{L}(P<0.0001)$ and producing an adjusted mean reduction from baseline in 2-hour 
postprandial glucose levels of $3.2 \mathrm{mmol} / \mathrm{L}(P<0.0001)$. Statistically significant and relevant treatment differences were observed for proinsulin/insulin ratio $(P=0.025)$, homeostasis model assessment (HOMA) $(P=0.049)$, and disposition index $(P=0.0005){ }^{4}$

\section{Safety and tolerability of linagliptin/ DPP-4 inhibitors}

\section{Adverse events}

The safety profile of DPP-4 inhibitors has been welldocumented during registration studies and to a varying degree through post-marketing pharmacovigilance. The most commonly reported adverse events include mild infections (nose, respiratory, and urinary tract) and headache. DPP-4 has effects beyond its proteolytic action, including T-cell activation and proliferation. The potential effect of DPP-4 inhibitors on the immune system has resulted in theoretical safety concerns associated with long-term use of DPP-4 inhibitors in humans. Data from long-term trials for up to 2 years for sitagliptin has not revealed relevant changes in laboratory parameters.

Because inhibition of DPP-8 and DPP-9, which are closely related to DPP-4, have been associated with toxicities in animals, it is important to note that linagliptin displays a more than 10,000 -fold selectivity compared to both of these enzymes. ${ }^{15}$ Linagliptin is less selective than FAB-alpha, an extracellular enzyme similar to DPP-4; DPP-8 and DPP-9 are intracellular enzymes. FAB-alpha is generally not present in normal adult tissue, but is expressed in stromal fibroblast and is up-regulated during tissue remodeling. The extent of FAB-alpha inhibition in vivo using therapeutic doses has not been reported, but safety and efficacy issues have not been raised. ${ }^{2}$

\section{Hypoglycemia}

The incidence of hypoglycemia for linagliptin as monotherapy or in combination with metformin and pioglitazone was comparable to placebo. When used as add-on therapy in patients with inadequate glycemic control treated with metformin and sulfonylurea or as add on to sulfonylurea monotherapy, an increased incidence of hypoglycemia was observed. ${ }^{16}$ A pooled analysis showed that linagliptin was well-tolerated, with a low risk of hypoglycemia. ${ }^{17}$

\section{Body weight gain}

No significant weight gain was observed in response to treatment with DPP-4 inhibitors, either as monotherapy or in combination therapy. However, in contrast to the effects of GLP-1 analogs, no weight loss was observed. ${ }^{17}$

\section{Drug interactions}

In vitro studies identified linagliptin as a substrate for CYP3A3 and as a weak inhibitor of the P450 system, ${ }^{8}$ but it exhibits no interactions with the enzymes in concentrations up to 50 $\mu \mathrm{M} .{ }^{15}$ This indicates that linagliptin is unlikely to affect the pharmacokinetics of agents metabolized by this system. ${ }^{2}$

Three small, open-labeled, randomized, crossover studies have been conducted to evaluate the potential interactions between linagliptin and metformin, between linagliptin and pioglitazone, and between linagliptin and sulfonylurea. Neither drug was shown to have a clinically meaningful effect on the pharmacokinetics of the other agent, indicating that these drugs can be co-administrated without dose adjustments of either drug. ${ }^{18-20}$

For up to 24 weeks, 2523 patients received linagliptin $5 \mathrm{mg}$ once daily, and 1049 have received placebo. The overall incidence of adverse events (AE) or serious AE with linagliptin was similar to those of placebo (AE 55.8\% versus $55.0 \%$; serious AE $2.8 \%$ versus $2.7 \%$ ). Overall aggregated infection was $19.5 \%$ for linagliptin and $21.4 \%$ for placebo. The most apparent differences in AE were upper respiratory tract infection (3.3\% versus $4.9 \%)$, headache $(2.9 \%$ versus $3.1 \%)$, urinary tract infection $(2.2 \%$ versus $2.7 \%)$, and nasopharyngitis (5.9\% versus $5.1 \%$ ) during linagliptin and placebo treatment, respectively. The incidences of disorders of the blood and lymphatic systems, hypersensitivity, cough, hepatic enzyme, and serum creatinine increase were low.

The incidence of hypoglycemia was $8.2 \%$ for linagliptin and $5.1 \%$ for placebo. The incidence was higher in patients who previously received sulfonylurea therapy $(20.7 \%$ and $13.3 \%$ ). In patients not receiving concomitant sulfonylureas, the incidence of hypoglycemia was very low with linagliptin in the total study population $(<1 \%)$ and in the elderly and patients with impaired renal function (both $<1 \%$ ).

Because of diverse biological activities of DPP-4, it has been hypothesized that inhibitors of its enzymatic activity may have on-target adverse effects, particularly carcinogenesis and/or infections. The concern regarding the potential for causing cancer is based on the actions of DPP-4 in tumor suppression and the fact that the Food and Drug Administration (FDA) adverse event reporting system database found an apparent increase in the reports of pancreatitis and pancreatic cancer among patients receiving sitagliptin or exenatide (GLP-1 receptor agonist). Review of these data showed that sitagliptin was not associated with increased reports of pancreatic, ${ }^{21}$ thyroid, or any other cancer. Overall, no studies have identified a causal relationship between DPP-4 inhibitors and cancer incidence. Results 
from the pooled analyses of linagliptin clinical studies reported the incidence of cancer in the linagliptin group and placebo group to be $0.2 \%$ and $0.5 \%$, respectively. ${ }^{17}$

A meta-analysis of randomized clinical trials with DPP-4 inhibitors excluded any relevant short-term effect of DPP-4 on the incidence of cancer, and suggested possible protection from cardiovascular events. ${ }^{21}$

\section{Linagliptin and hepatic impairment}

The pharmacokinetics of linagliptin were investigated in an open-label, parallel-group, single center study enrolling patients with mild $(\mathrm{n}=8)$, moderate $(\mathrm{n}=9)$, or severe $(\mathrm{n}=8)$ renal impairment and 8 healthy subjects. All received linagliptin $5 \mathrm{mg}$ for 7 days.

In patients with mild and moderate hepatic impairment, steady-state linagliptin exposure was slightly lower than in healthy subjects. After a single dose, the area under the curve for time 0 to 24 hours (AUC0-24) was shown to be similar in patients with severe hepatic impairment and in healthy subjects, whereas maximum concentration $\left(\mathrm{C}_{\max }\right)$ was lower. Accumulation evaluated based on $\mathrm{AUC}$ or $\mathrm{C}_{\max }$ and renal excretion of unchanged linagliptin $(\leq 7 \%)$ were comparable across groups. Mean plasma DPP-4 inhibition was similar in healthy (91\%), patients with mild (90\%) and moderate $(89 \%)$ hepatic impairment at steady-state trough levels, and in patients with severe hepatic impairment for $24 \mathrm{~h}$ after a single dose (84\%).

Mild, moderate, or severe hepatic impairment did not result in an increase in linagliptin exposure after single and multiple dosing. Thus, dose adjustment of linagliptin is not required in patients with liver impairment.

Because linagliptin is predominantly eliminated without involvement of hepatic metabolizing function, high enzyme binding, in addition to a low rate of hepatic metabolism, results in hepato-biliary excretion of predominantly unchanged linagliptin. The low concentration of unbound linagliptin may easily be eliminated by the liver. ${ }^{22}$

\section{Linagliptin and renal impairment}

The effect of renal impairment on linagliptin excretion was investigated in a single-dose parallel-group, open-label study in subjects with mild $(\mathrm{n}=6)$, moderate $(\mathrm{n}=6)$, and severe renal impairment ( $\mathrm{n}=10$, without T2DM $n=6)$, as well as in those with end-stage renal disease $(n=6)$ and subjects with normal renal function.

Renal excretion of unchanged linagliptin was $<7 \%$ in all groups. The degree of renal impairment did not affect mean plasma linagliptin concentration-time profiles. Steady-state
AUC and $\mathrm{C}_{\text {max }}$ values were not affected by the degree of renal impairment. The accumulation half-life of linagliptin ranged from 14-15 hours in subjects with normal renal function to 18 hours in those with severe renal impairment. Only a weak correlation was observed between creatinin clearance and steady-state exposure. Therefore, linagliptin doses do not need to be adjusted in T2DM patients with impaired renal function. ${ }^{23}$

\section{Linagliptin and cardiovascular (CV) safety}

In a meta-analysis of a Phase III program involving 5239 treated T2DM patients, 3319 received linagliptin once daily, and 1920 received comparators (placebo, $n=977$; glimipiride 1-4 mg, $\mathrm{n}=781$; voglibose $0.6 \mathrm{mg}, \mathrm{n}=162$ ).

Primary CV events occurred in $11(0.3 \%)$ patients receiving linagliptin and in $23(1.2 \%)$ receiving comparators. The hazard ratio (HR) for the primary endpoint showed a significantly lower risk for linagliptin than for comparators (HR 0.34 [95\% confidence intervals (CI) $0.16-0.70]$ ), as did estimates for all secondary endpoints (HR ranging from $0.34-0.55$ [all upper $95 \% \mathrm{CI}<1.0]$ ).

These results support the hypothesis that linagliptin may have CV benefits in patients with T2DM. Currently, the CAROLINA study (CARdiOvascular Outcome Study of the DPP-4 inhibitor), the first large outcomes study to directly compare a DPP-4 inhibitor versus a sulfonylurea (glimipiride) as second-line therapy (as a supplement to metformin) is testing this hypothesis. ${ }^{24}$

Rodent studies have indicated that incretin hormones may have anti-atherosclerotic actions, with reduced atherosclerotic lesions observed following treatment with DPP-4 inhibitors. ${ }^{25}$ However, long-term CV safety is unclear.

\section{Other effects of DPP-4 inhibitors} Neuroprotection and wound healing In rodents, neuroprotective effects of GLP-1 have been demonstrated, and studies in diabetic rats have suggested that the increased endogenous GLP-1 concentration that occurs following by DPP-4 inhibition may reduce peripheral nerve degeneration. ${ }^{26}$

\section{Beta-cell function}

DPP-4 inhibitors have been shown to improve beta-cell mass and function in animal models as well as in human in vitro studies. ${ }^{16}$ In a phase III study, statistically significant and clinically relevant differences were observed for the proinsulin/insulin ratio, HOMA, and disposition index. ${ }^{4}$ 


\section{Lipids}

A meta-analysis including 17 clinical trials found that DPP-4 inhibitors are associated with a significant reduction in total cholesterol, which may contribute to reduced cardiovascular risk. $^{27}$

\section{Place of linagliptin in the management of T2DM Gliptins as monotherapy}

All gliptins have been shown to be superior to placebo, showed slightly less reduction in $\mathrm{HbA}_{1 \mathrm{c}}$ levels compared with metformin, and similar improvements compared with a sulfonylurea and a thiazolidinedione or acarbose. Hypoglycemic events are rare with both a DPP-4 inhibitor and metformin compared with sulfonylurea, for example. Weight loss was generally greater with metformin than with any tested DPP-4 inhibitor, but no weight gain was observed for DPP-4 inhibitors as compared with sulfonylurea and thiazolidinedione (pioglitazone $30 \mathrm{mg}$ and rosiglitazone $8 \mathrm{mg}$ ). ${ }^{8}$ As described below, four long-term ( $\geq 24$ week), randomized, double-blinded, placebo-controlled Phase III trials with linagliptin $5 \mathrm{mg}$ oral daily either as monotherapy or add-on therapy have been completed.

\section{Linagliptin as monotherapy}

The effect of linagliptin monotherapy on glycemic control and markers of beta-cell function in patients with inadequately controlled T2DM was investigated in 503 T2DM patients (linagliptin, $\mathrm{n}=336$; placebo, $\mathrm{n}=167$ ). Patients included those who were either treatment-naïve before inclusion or those who underwent a washout period before receiving the trial treatment. The mean age was 55.7 years, $48.3 \%$ were men, and the ratio of Caucasian:Asian patients was 53.7\%:46.1\%. Linagliptin resulted in a sustained clinically significant improvement in glycemic control and enhanced parameters of beta-cell function. The safety profile of linagliptin was comparable to that of placebo. ${ }^{4}$

Available data do not support the initial use of a DPP-4 inhibitor rather than the reference drug metformin, except in patients for whom metformin is either not tolerated (gastrointestinal adverse events) or contraindicated (eg, renal insufficiency) according to the guidelines from the National Institute of Clinical Excellence. ${ }^{8}$

\section{Linagliptin as add-on to metformin}

The safety and efficacy of linagliptin as add-on therapy to metformin ( $\geq 1500 \mathrm{mg} /$ day) was investigated in $701 \mathrm{~T} 2 \mathrm{DM}$ patients (metformin + linagliptin $\mathrm{n}=524$; metformin + placebo $=177)$. Compared to placebo, linagliptin showed significant reductions in adjusted mean changes from baseline of $\mathrm{HbA}_{\mathrm{lc}}(-0.49 \% \mathrm{vs} 0.15 \%)$, fasting plasma glucose (FPG) $(-0.59 \%$ vs $0.58 \% \mathrm{mmol} / \mathrm{L})$, and 2 -h post-prandial plasma glucose $(-2.7 \%$ vs $1.0 \% \mathrm{mmol} / \mathrm{L})($ all $P<0.0001)$. Hypoglycemia rarely occurred (linagliptin $0.6 \%$ versus placebo $2.8 \%$ ). Body weight did not change significantly from baseline ( $-0.4 \mathrm{~kg}$ linagliptin versus -0.5 placebo) ${ }^{28}$

\section{Linagliptin in combination with pioglitazone}

The safety and efficacy of initial combination therapy with linagliptin and pioglitazone $(30 \mathrm{mg})$ was investigated in 389 T2DM patients (pioglitazone + linagliptin, $\mathrm{n}=259$, pioglitazone + placebo $=130)$.

After 24 weeks, the pioglitazone + linagliptin combination versus placebo + pioglitazone improved adjusted mean $\mathrm{HbA}_{1 \mathrm{c}}$ by $-1.06 \%( \pm 0.06)$ versus $-0.56 \%( \pm 0.09)$. The difference was significant $(-0.51 \%, 95 \% \mathrm{CI}-0.71$ to 0.30 ; $P<0.0001)$. The linagliptin group was more likely to achieve $\mathrm{HbA}_{1 \mathrm{c}}<7.0 \%$ (42.9\% versus $\left.30.5 \%, P=0.0051\right)$.

The reductions in FPG were -1.8 versus $-1.0 \mathrm{mmol} / \mathrm{L}$, respectively, with a difference of $-0.8 \mathrm{mmol} / \mathrm{L}(95 \% \mathrm{CI}-1.2$ to $0.4 ; P<0.0001)$. Beta-cell function, determined based on the ratio of relative change in adjusted mean HOMA for insulin resistance (HOMA-IR) and disposition index, was shown to improve. The proportion of patients that experienced at least one AE did not differ between groups. Hypoglycemic episodes (all mild) occurred in 1.2\% of subjects receiving linagliptin versus none in the placebo group. ${ }^{29}$

\section{Linagliptin as add-on to metformin and sulfonylurea}

The safety and efficacy of linagliptin in combination with metformin and sulfonylurea was investigated in 1058 T2DM patients (metformin, sulfonylurea + linagliptin $\mathrm{n}=793$; metformin, sulfonylurea + placebo $=265$ ) .

After 24 weeks, the placebo-corrected linagliptin $\mathrm{HbA}_{1 \mathrm{c}}$ adjusted mean change from baseline was $-0.62 \%(95 \%$ CI $-0.73 \%$ to $-0.50 \% ; P<0.0001)$. More participants achieved an $\mathrm{HbA}_{1 \mathrm{c}}<7 \%$ with linagliptin compared to placebo (29.2\% versus $8.1 \%, P<0.0001)$. FPG was reduced by $-0.7 \mathrm{mmol} / \mathrm{L}, 95 \% \mathrm{CI}-1.0$ to $-0.4 ; P<0.0001$ ) by linagliptin vs placebo, and beta cell function, and HOMA improved. The incidence of severe adverse events was low in both the linagliptin and placebo groups (2.4\% versus $1.5 \%)$. Symptomatic hypoglycemia occurred in $16.7 \%$ versus $10.3 \%$ 
of the groups (severe in $2.7 \%$ versus $4.8 \%$ ). No significant weight changes were noted. ${ }^{30}$

Combination therapy with linagliptin was well-tolerated and produced significant and clinically meaningful improvements in glycemic control.

Linagliptin may be a valuable treatment option for individuals with inadequate glycemic control despite ongoing combination therapy with metformin and a sulfonylurea ${ }^{28}$ or when metformin is not well-tolerated, such as in patients with renal impairment. ${ }^{29}$

\section{Gliptins in combination with insulin in T2DM patients}

Reductions in $\mathrm{HbA}_{1 \mathrm{c}}$ with additional $0.3 \%-0.6 \%$ have been reported with the addition of sitagliptin, vildagliptin, saxagliptin, or alogliptin to insulin treatment. ${ }^{8}$ Thus adding a DPP-4 inhibitor to insulin therapy may be useful for T2DM patients to improve glucose control without increasing hypoglycemia and possibly limiting weight gain. Further studies are necessary to explore the role of DPP-4 inhibitors (and linagliptin) added to optimized insulin regimes, as previous studies were performed in patients receiving basal insulin therapy. ${ }^{8}$ Linagliptin is, however, not currently approved for co-administration with insulin.

\section{Linagliptins's place in therapy}

In Europe, linagliptin is indicated for the treatment of T2DM to improve glycemic control in adults either as (1) monotherapy in patients inadequately controlled by diet and exercise alone and for whom metformin is inappropriate due to intolerance or contraindicated due to renal impairment or as (2) combination therapy, in combination with metformin when diet and exercise plus metformin alone do not provide adequate glycemic control, or in combination with a sulfonylurea and metformin when diet and exercise plus dual therapy with these medicinal products do not provide adequate glycemic control. ${ }^{14}$ Linagliptin is also effective when combined with pioglitazone. Dosing is once daily and dose reduction in those with renal impairment is unnecessary.

\section{Disclosure}

Lene Hoimark and Torben Laursen disclose no conflicts of interest. Jørgen Rungby has received consultancy fees from Boehringer-Ingelheim and other producers of DPP-4 inhibitors.

\section{References}

1. Horie Y, Kanada S, Watada H, et al. Pharmacokinetic, pharmacodynamic, and tolerability profiles of the dipeptidyl peptidase- 4 inhibitor linagliptin: a 4-week multicenter, randomized, double-blind, placebo-controlled phase IIa study in Japanese type 2 diabetes patients. Clin Ther. 2011;33:973-989.
2. Deacon CF, Holst JJ. Linagliptin, a xanthine-based dipeptidyl peptidase-4 inhibitor with an unusual profile for the treatment of type 2 diabetes. Expert Opin Investig Drugs. 2010;19:133-140.

3. Forst T, Uhlig-Laske B, Ring A, Ritzhaupt A, Graefe-Mody U, Dugi KA. The oral DPP-4 inhibitor linagliptin significantly lowers $\mathrm{HbA}_{1 \mathrm{c}}$ after 4 weeks of treatment in patients with type 2 diabetes mellitus. Diabetes Obes Metab. 2011;13:542-550.

4. Del PS, Barnett AH, Huisman H, Neubacher D, Woerle HJ, Dugi KA. Effect of linagliptin monotherapy on glycaemic control and markers of beta-cell function in patients with inadequately controlled type 2 diabetes: a randomized controlled trial. Diabetes Obes Metab. 2011;13:258-267.

5. Forst T, Pfutzner A. Linagliptin, a dipeptidyl peptidase-4 inhibitor with a unique pharmacological profile, and efficacy in a broad range of patients with type 2 diabetes. Expert Opin Pharmacother. 2012;13:101-110.

6. Del Prato S. Linagliptin for the treatment of type 2 diabetes. Expert Opin Pharmacother. 2011;12:2759-2762.

7. Baetta R, Corsini A. Pharmacology of dipeptidyl peptidase-4 inhibitors: similarities and differences. Drugs. 2011;71:1441-1467.

8. Scheen AJ. A review of gliptins in 2011. Expert Opin Pharmacother. 2012;13:81-99.

9. Retlich S, Duval V, Ring A, et al. Pharmacokinetics and pharmacodynamics of single rising intravenous doses $(0.5 \mathrm{mg}-10 \mathrm{mg})$ and determination of absolute bioavailability of the dipeptidyl peptidase- 4 inhibitor linagliptin (BI 1356) in healthy male subjects. Clin Pharmacokinet. 2010;49:829-840.

10. Huttner S, Graefe-Mody EU, Withopf B, Ring A, Dugi KA. Safety, tolerability, pharmacokinetics, and pharmacodynamics of single oral doses of BI 1356, an inhibitor of dipeptidyl peptidase 4, in healthy male volunteers. J Clin Pharmacol. 2008;48:1171-1178.

11. Graefe-Mody U, Giessmann T, Ring A, Iovino M, Woerle HJ. A randomized, open-label, crossover study evaluating the effect of food on the relative bioavailability of linagliptin in healthy subjects. Clin Ther. 2011;33:1096-1103.

12. Heise T, Graefe-Mody EU, Huttner S, Ring A, Trommeshauser D, Dugi KA. Pharmacokinetics, pharmacodynamics and tolerability of multiple oral doses of linagliptin, a dipeptidyl peptidase-4 inhibitor in male type 2 diabetes patients. Diabetes Obes Metab. 2009;11:786-794.

13. Blech S, Ludwig-Schwellinger E, Grafe-Mody EU, Withopf B, Wagner K. The metabolism and disposition of the oral dipeptidyl peptidase-4 inhibitor, linagliptin, in humans. Drug Metab Dispos. 2010; 38:667-678.

14. [Trajenta product information]. Ingelheim am Rhein: Boehringer Ingelheim GmbH. Available from: http://www.ema.europa.eu/docs/en GB/document_library/EPAR_-_Product_Information/human/002110/ WC500115745.pdf. Accessed March 13, 2012.

15. Eckhardt M, Langkopf E, Mark M, et al. 8-(3-(R)-aminopiperidin1-yl)-7-but-2-ynyl-3-methyl-1-(4-methyl-quinazolin-2-ylme thyl)3,7-dihydropurine-2,6-dione (BI 1356), a highly potent, selective, long-acting, and orally bioavailable DPP-4 inhibitor for the treatment of type 2 diabetes. J Med Chem. 2007;50:6450-6453.

16. Barnett AH. Linagliptin: a novel dipeptidyl peptidase 4 inhibitor with a unique place in therapy. Adv Ther. 2011;28:447-459.

17. Schernthaner G, Barnett AH, Emser A, et al. Safety and tolerability of linagliptin: a pooled analysis of data from randomized controlled trials in 3572 patients with type 2 diabetes mellitus. Diabetes Obes Metab. 2012;14:470-478.

18. Graefe-Mody U, Rose P, Ring A, Zander K, Iovino M, Woerle HJ. Assessment of the pharmacokinetic interaction between the novel DPP-4 inhibitor linagliptin and a sulfonylurea, glyburide, in healthy subjects. Drug Metab Pharmacokinet. 2011;26:123-129.

19. Graefe-Mody EU, Jungnik A, Ring A, Woerle HJ, Dugi KA. Evaluation of the pharmacokinetic interaction between the dipeptidyl peptidase-4 inhibitor linagliptin and pioglitazone in healthy volunteers. Int J Clin Pharmacol Ther. 2010;48:652-661.

20. Graefe-Mody EU, Padula S, Ring A, Withopf B, Dugi KA. Evaluation of the potential for steady-state pharmacokinetic and pharmacodynamic interactions between the DPP-4 inhibitor linagliptin and metformin in healthy subjects. Curr Med Res Opin. 2009;25:1963-1972. 
21. Monami M, Dicembrini I, Martelli D, Mannucci E. Safety of dipeptidyl peptidase-4 inhibitors: a meta-analysis of randomized clinical trials. Curr Med Res Opin. 2011;27(Suppl 3):57-64.

22. Graefe-Mody U, Rose P, Retlich S, et al. Pharmacokinetics of linagliptin in subjects with hepatic impairment. Br J Clin Pharmacol. 2012;74: $75-85$.

23. Graefe-Mody U, Friedrich C, Port A, et al. Effect of renal impairment on the pharmacokinetics of the dipeptidyl peptidase-4 inhibitor linagliptin(*). Diabetes Obes Metab. 2011;13:939-946.

24. Johansen OE, Neubacher D, vonEynatten M, Patel S, Woerle HJ. Cardiovascular safety with linagliptin in patients with type 2 diabetes mellitus: A pre-specified, prospective, and adjudicated meta-analysis of a phase 3 programme. Cardiovasc Diabetol. 2012;11:3.

25. Ta NN, Schuyler CA, Li Y, Lopes-Virella MF, Huang Y. DPP-4 (CD26) inhibitor alogliptin inhibits atherosclerosis in diabetic apolipoprotein E-deficient mice. J Cardiovasc Pharmacol. 2011;58:157-166.

26. Davidson EP, Coppey LJ, Dake B, Yorek MA. Treatment of streptozotocin-induced diabetic rats with alogliptin: effect on vascular and neural complications. Exp Diabetes Res. 2011;2011:Article ID 810469.
27. Monami M, Lamanna C, Desideri CM, Mannucci E. DPP-4 Inhibitors and Lipids: Systematic Review and Meta-Analysis. Adv Ther. 2012;29: 14-25.

28. Taskinen MR, Rosenstock J, Tamminen I, et al. Safety and efficacy of linagliptin as add-on therapy to metformin in patients with type 2 diabetes: a randomized, double-blind, placebo-controlled study. Diabetes Obes Metab. 2011;13:65-74.

29. Gomis R, Espadero RM, Jones R, Woerle HJ, Dugi KA. Efficacy and safety of initial combination therapy with linagliptin and pioglitazone in patients with inadequately controlled type 2 diabetes: a randomized, double-blind, placebo-controlled study. Diabetes Obes Metab. 2011;13:653-661.

30. Owens DR, Swallow R, Dugi KA, Woerle HJ. Efficacy and safety of linagliptin in persons with type 2 diabetes inadequately controlled by a combination of metformin and sulphonylurea: a 24-week randomized study. Diabet Med. 2011;28:1352-1361.

\section{Publish your work in this journal}

Diabetes, Metabolic Syndrome and Obesity: Targets and Therapy is an international, peer-reviewed open-access journal committed to the rapid publication of the latest laboratory and clinical findings in the fields of diabetes, metabolic syndrome and obesity research. Original research, review, case reports, hypothesis formation, expert opinion and commentaries are all considered for publication. The manuscript management system is completely online and includes a very quick and fair peer-review system, which is all easy to use. Visit http://www.dovepress.com/testimonials.php to read real quotes from published authors.

Submit your manuscript here: http://www.dovepress.com/diabetes-metabolic-syndrome-and-obesity-targets-and-therapy-journal 